\title{
ÉTICA Y POLÍTICA: MORAL CÍVICA PARA UNA CIUDADANÍA COSMOPOLITA
}

\author{
Adela CORTINA \\ Universidad de Valencia
}

\section{Tres décadas de filosofía práctica}

Las últimas décadas del siglo $\mathrm{XX}$ han ido conduciendo a la filosofía práctica a ocuparse de un tema tan acreditado en las tradiciones filosóficas de Occidente como es el de la ciudadanía. Los años setenta y parte de los ochenta vivieron las agrias polémicas entre Modernidad y Postmodernidad, las crisis del capitalismo tardío con sus diferentes lecturas filosóficas, la "revolución neoconservadoras, la elaboración de teorías de la justicia de muy diverso cuño, y saludaron el nacimiento de una forma de hacer ética, aparentemente antigua pero realmente innovadora, como es la ética aplicada.

Entrados los ochenta, saltó a la palestra la encarnizada "querella de los universalistas y los comunitarios", vivida al menos en una doble versión. En la versión anglosajona, liberales como Rawls, Dworkin, Larmore o Ackerman, fueron tachados de individualistas, de defender como núcleo de la sociedad al individuo y sus derechos, por parte de autores como MacIntyre o Sandel que, sin querer recibir el nombre de comunitarios, representaban la "crítica comunitaria al liberalismo", más que una alternativa efectiva ${ }^{1}$. Sería más tarde cuando Amitai Etzioni lanzaría su "Plataforma Responsiva", en forma de revis$\mathrm{ta}^{2}$ como movimiento defensor de una alternativa comunitaria en la teoria y $47-64$.

1 M. WALzer, "La crítica comunitarista del liberalismo», en La Política, 1 (1996), págs.

2 La revista "The Responsive Community. Rights and Responsabilities» nace en 1991. 
en la práctica. Trataba desde ella de responder a las críticas recibidas por los comunitarios de permanecer en un estadio convencional en el desarrollo de la conciencia moral social, sentando las bases de un comunitarismo moderno, postconvencional, en el que se aunan el orden social (la tradición conservadora) y la autonomía personal (el orden moderno) ${ }^{3}$.

En el mundo germano, por su parte, la querella de los universalistas y los comunitarios se encarnó en el enfrentamiento entre los partidarios de la kantiana Moralität (Apel, Habermas, Kohlberg) y los defensores de la hegeliana Sittlichkeit (Spaemann, Bubner, Marquard). Acusados los primeros de apostar por un universalismo abstracto, replicaban a los hegelianos que, a fin de cuentas, el hegelianismo llega a un grado de concreción tal en su universalismo que acaba ligándolo a los rasgos de una comunidad política concreta ${ }^{4}$.

La ética aplicada, por su parte, avanza prodigiosamente, y los problemas de fundamentación de la moral van quedando en un discreto segundo término en comparación con el crecimiento de la aplicación en sus diferentes vertientes: bioética, ética de la economía y de la empresa, GenÉtica, ética de la información, ética ecológica, ética de las profesiones 5 .

En los años noventa el viejo concepto de ciudadanía sale de nuevo a la luz por razones tanto de ética y politica vividas como de ética y política pensadas. $\mathrm{La}$ configuración de unidades transnacionales, como la Unión Europea, genera un modelo de comunidad política distinto del propio del Estado nacional ${ }^{6}$, con

3 A. Etzioni, La Nueva Regla de Oro, Barcelona, Paidós, 1999.

4 W. Kunlmann (Hg.), Moralität und Sittlichkeit, Frankfurt, Suhrkamp, 1986; A. CoRTina, Etica sin moral, Madrid, Tecnos, 1990, cap. 4.

5 La producción en ética aplicada es inabarcable. Como muestra podrían citarse: $D$. Gracia, Fundamentos de bioética, Madrid, EUDEMA, 1988; J. GaFo (comp.) Dilemas éticos de la medicina actuah Madrid, Univ. Pont. Comillas, 1986; J. GAFO, Diez palabras clave en bioética, Estella, VD, 1993; N. MARTIN SOSA, Ética ecologica, Madrid, 1990; A. CorTINA, Ética aplicada y democracia radical, Madrid, Tecnos, 1993; «El estatuto de la ética aplicada. Hermenéutica crítica de las actividades humanas", en Isegoría, 13 (1996), págs. 119-134; Ciudadanos del mundo, Madrid, Alianza, 1997; A. Cortina, J. Conill, A. Domingo, D. GarCía MarzA, Ética de la empresa, Madrid, Trotta, 1994; A. EDEL, E. FlOWER, F. W. O'CONNOR, Critique of Applied Ethics, Philadelphia, Temple University Press, 1994; J. L. Fernandez, A. HORTAL, Ética de las profesiones, Madrid, Univ. Pont. Comillas, 1994; E. BONETE (coord.), Eticas de la Información y Deontologias del periodismo, Madrid, Tecnos, 1995; L. K. SOSOE (dir.), La vie des normes \& l'esprit des lois, Quebec/Paris, Harmattan, 1998; J. M. LoZANO, Ética y empresa, Madrid, Trotta, 1999.

6 J. Habermas, La inclusión del otro, Barcelona, Paidós, 1999, Parte II. 
lo cual surge la pregunta por el tipo de ciudadano que es miembro de esas comunidades, un ciudadano que, al menos, debe compaginar dos identidades ciudadanas. Compaginar esas dos identidades supone no sólo aclarar si una de ellas debe tener prioridad sobre otra, sino también tratar de construir una historia común, unos símbolos comunes, que den cuerpo a la nueva identidad ciudadana transnacional ${ }^{7}$.

Por otra parte, el resurgir de los nacionalismos en buena parte de Europa pone también sobre el tapete la candente cuestión de cómo conciliar en una misma persona dos identidades políticas distintas que, desde la perspectiva nacionalista, entran claramente en conflicto ${ }^{8}$. Una de esas identidades le viene al ciudadano de pertenecer a una subunidad política, que no es un Estado nacional pero pretende serlo, o al menos cobrar una configuración política muy especial en el Estado nacional. Conseguir un acomodo de identidades mediante un Estado autonómico o federal, con federalismo simétrico o asimétrico, es una de las posibles soluciones, la otra, formar un Estado nacional nuevo?.

Junto a estas dos razones cotidianas para abordar el tema de la ciudadanía, una tercera, el siempre doloroso fenómeno de las migraciones forzadas, obliga a preguntar por las distintas formas de pertenecer a un Estado nacional y por los derechos que genera cada una de ellas. Porque, sin duda, el primero de los bienes que otorga una comunidad política a quienes forman parte de ella es justamente la pertenencia (membership) ${ }^{10}$, pero existen muchas formas de pertenecer, una de las cuales es la ciudadanía.

La crisis del Estado del bienestar, que había dado carta de naturaleza al concepto de ciudadanía social ${ }^{11}$, obliga a replantear qué derechos deben ser protegidos por un Estado social de Derecho que pretenda ser legítimo ${ }^{12}$, y,

7 D. Heater, Citizenship, London and New York, Longman, 1990; A. CorTinA, Ciudadanos del mundo.

8 B. ANDERSON, Imagined Communities, Londres, Verso, 1991; E. GeLlNER, Naciones y nacionalismos, Madrid, Alianza, 1994; N. LOPEZ CALERA, El nacionalismo. (Culpable o inocente), Madrid, Tecnos, 1995; Á. Castineira (dir), Comunitat i Nacio, Barcelona, Proa, 1995; D. MiLLER, Sobre la nacionalidad, Barcelona, Paidós, 1997.

9 W. KYMLICKA, «Federalismo, nacionalismo y multiculturalismo", en Revista Internacional de Filosofia Politica, 7 (1996), págs. 20-54.

10 M. WALZER, Esferas de la justicia, México, F. C. E., 1993, cap. II.

11 T. H. Marshall, Ciudadania y clase sociah Madrid, Alianza, 1998.

12 A. Cortina, Ciudadanos del mundo, cap. III. 
por su parte, la cuestión del fenómeno multicultural en sociedades liberales y la pujanza de las ideologías "grupalistas" fuerzan a revisar el concepto de ciudadanía y a diseñar los de "ciudadanía multicultural" ${ }^{13}$ y "ciudadanía diferenciada" ${ }^{14}$.

En lo que hace a la ética y la política "pensadas, es decir, a la ética filosófica y la filosofía política, sin duda los fenómenos citados obligan a poner sobre el tapete el candente tema de la ciudadanía, y a ello se añade el hecho de que esta cuestión permite sumar los esfuerzos de liberales y comunitarios, al conjugar la preocupación de los primeros por la justicia y los derechos con la preocupación de los comunitarios por la pertenencia a la comunidad y por la responsabilidad hacia ella ${ }^{15}$. Por decirlo de forma un tanto despachada, la noción de ciudadanía podría producir un híbrido de Rawls y Etzioni, una unión de la idea liberal de "ciudadanos libres e iguales" y la idea comunitaria del "ciudadano perteneciente» a una comunidad y "responsable de ella».

Sin embargo, poner un tema sobre el tapete de la discusión filosófica es la mejor forma de empezar a descubrir lo mucho que se ignora sobre él. Y por eso se hizo necesario ir aclarando paulatinamente qué entendemos en el cambio de siglo por "un verdadero ciudadano, en el sentido que Hegel daba a esta acepción de verdad, como acuerdo con un concepto que se deja a su vez criticar por la realidad" ${ }^{16}$. Distintas tradiciones filosóficas se aprestaban a esclarecer el contenido de esa ciudadanía tomada en el pleno sentido de la palabra, y la prudencia desaconsejaba prescindir de lo mucho de bueno que aportaban algunas de ellas.

\section{Ciudadanía cosmopolita}

Curiosamente, lo que revelaba cualquiera de los tratamientos del concepto de ciudadanía es que encierra en su seno una dialéctica de inclusión y exclusión,

13 Ch. TAYLOR, El multiculturalismo y la "política del reconocimiento", México, F.C.E., 1993; W. KYMLICKA, Ciudadanía Multicultural, Barcelona, Paidós, 1996.

14 I. M. YounG, "Polity and Group Difference: A Critique of the Ideal of Universal Citizenship», en R. BEINER (ed.), Theorizing Citizenship, State of New York Press, 1995, págs. 250-274.

15 W. KYMLICKA/W. Norman, “El retorno del ciudadano», en La Política, 3 (1997), 5-40; A. Cortina, Ciudadanos del mundo, Introducción y cap. 1.

16 De esbozar las distintas dimensiones de la ciudadanía me he ocupado en los diferentes capítulos de Ciudadanos del mundo. 
de identidad y diferencia que, tomada en serio, exige reformular totalmente el concepto. En efecto, el ciudadano es el miembro de una comunidad política que es en ese respecto igual a los demás miembros, pero a la vez diferente de quienes no son ciudadanos de esa comunidad. Lo cual es perfectamente comprensible en las sociedades situadas en el nivel convencional en el desarrollo de la conciencia moral, en las que, a fin de cuentas, lo justo se identifica con las normas de la comunidad. Pero, ipuede mantenerse esta dialéctica externointerno, inclusión-exclusión en sociedades situadas en el nivel postconvencional en el desarrollo de la conciencia moral?

Si las bases de un Estado nacional postconvencional son las que Kant propone como propias de una constitución republicana ( 1 l. la libertad de cada miembro de la sociedad, en cuanto hombre. 2. la igualdad de éste con cualquier otro, en cuanto súbdito. 3. La independencia de cada miembro de una comunidad, en cuanto ciudadanos) ${ }^{17}$, estamos afirmando que esas sociedades deben tener por justo lo que responde a principios universalistas, con lo cual resulta muy difícil mantener a la vez el principio de la exclusión. Una vez introducido el germen del universalismo, resulta difícil seguir manteniendo que algo queda "fuera». La pregunta es entonces: ¿no puede haber, a fin de cuentas, un ideal de ciudadanía que vaya más allá del cosmopolitismo desarraigado y del parroquialismo inhumano, es decir un cosmopolitismo arraigado? ¿Es el cosmopolitismo un punto de vista moral, o viene obligado políticamente por ese "patriotismo de la Constitución", que va mucho más allá de las eticidades concretas?

Una primera respuesta a esta pregunta podría venir ejemplificada por la posición defendida por Habermas tanto en Facticidad y validez como en $L a$ inclusión del otro: la noción de ciudadanía, al ser política, se remitiría a un principio de legitimación distinto al moral. El principio de legitimación de normas jurídico-políticas, ligado a la idea de ciudadano, se aplicaría a las comunidades políticas concretas, y tendría fuerza obligatoria para aquellos que han sellado un hipotético pacto social. El principio moral, por el contrario, se aplicaría a las normas para cuya justificación es preciso tener en cuenta los intereses de toda la humanidad. En efecto, en los dos trabajos citados distingue Habermas

17 I. KANT, "En torno al tópico», en Teoría y praxis, Madrid, Tecnos, 1986, 27. Pasajes paralelos en La paz perpetua, Madrid, Tecnos, 1985, 15; La metafisica de las costumbres, Madrid, Tecnos, 1989, 143. 
entre un principio racional supremo -el Principio del Discurso-y dos especificaciones del mismo: el Principio Moral, que «resulta de una especificación del principio general del discurso para aquellas normas de acción que sólo pueden justificarse desde la perspectiva de tener en cuenta a todos los afectados", y el Principio político de la Democracia, que se aplica a «aquellas normas de acción que se presentan en forma de derecho y que pueden justificarse con ayuda de razones pragmáticas, de razones ético-políticas y de razones morales, y no sólo con ayuda de razones morales» ${ }^{18}$.

Que esta arquitectónica resulte aceptable es cuestión que merece un tratamiento específico y que Apel ha discutido ampliamente ${ }^{19}$, aquí me limito a recoger el hecho de que la noción de ciudadanía sea preferentemente política y, en ese sentido, se refiera a la dimensión de pertenencia de una persona a una comunidad concreta, comunidad que, al menos hipotéticamente, se configura por un contrato entre sus miembros, y cuyas normas se legitiman sobre la base de razones pragmáticas, éticas (referidas a la eticidad concreta) y morales. La tradicional distinción entre el "ciudadano" y el "hombre» nos permitiría — según Habermas - limitar la ética política al ámbito del ciudadano y orientarla por el Principio de la Democracia, mientras que el «hombre» se regiría por el Principio Moral. Con esta solución habríamos aprovechado la distinción kantiana entre una autonomía moral, ligada al imperativo categórico, y una autonomía política, que debe tener en cuenta el hecho de que el móvil jurídico puede ser patológico, de suerte que para construir una paz perpetua es legítimo el uso de imperativos hipotéticos en su doble vertiente: habilidad técnica y consejos prudenciales.

Sin embargo, autores como Beiner proponen una tercera vía entre las dos mencionadas, una "ciudadanía republicana", que vendría a prolongar una línea abierta por Rousseau en el capítulo 8 del Libro 4 de El Contrato social. En este texto rousseauniano podríamos distinguir tres caminos distintos: 1) el liberal, que constituye una secularización del universalimo cristiano y que, por lo tanto, es anti-cívico, 2) el nacionalista, que prolonga la tradición de las «religiones nacionales" precristianas, que son a fin de cuentas parroquianas $\mathrm{e}$

18 J. Habermas, Facticidad y validez, Madrid, Trotta, 1998, 9. 173; La inclusion del otro, Barcelona, Paidós, 1999, cap. I.

19 K. O. APEL, Auseinandersetzungen in Erprobung des transzendentalpragmatischen Ansatzes, Frankfurt, Suhrkamp, 1998, cap. 11, 12 y 13; A. CORTiNA y J. ConiLl, "Pragmática Trascendental, en M. DASCAL (ed.), Filosofia del Lenguaje II. Pragmática, Madrid, Trotta, 1999, págs. 137-166.; Número 183 (1999) de la Revista Anthropos, monográfico sobre K. O. APEL. 
inhumanas ${ }^{20}, 3$ ) un tercer camino para la ciudadanía propia de una religión cívica todavía no existente, que combinaría el universalismo del cristianismo y el carácter cívico de las religiones nacionales. Ese camino - viene a concluir Beiner - todavía no está trazado ${ }^{21}$.

$Y$, sin embargo, el universalismo ético podría prestarnos un hilo conductor en la tarea de ir desbrozando el terreno para construir el nuevo camino, porque tal vez más que buscar una religión civil se trataría de ir descubriendo los rasgos de una ética cívica universalista.

La necesidad de una ética universal fue anunciada claramente por Apel en su Transformación de la filosofia (1973), al indicar que los efectos universales de la racionalidad científico-técnica deberían ser dirigidos desde una razón moral asimismo universal, si no queremos que resulten frecuentemente dañinos, más que beneficiosos. Las morales fragmentadas, vividas en niveles locales, carecen de la lucidez y la fuerza imprescindibles para enfrentar retos universales ${ }^{22}$.

El hecho de que en los años noventa se haya tomado mundialmente conciencia de que vivimos un imparable proceso de globalización ha obligado a desear una moral universalista incluso a los más renuentes. Se habla de "ética global" (H.Küng), de "mundialización" (A. Touraine), de "globalización ética" (Apel), y todo ello con el abierto mensaje de que es imprescindible contar con una ética universal en tiempos de globalización ${ }^{23}$, en los que resulta ineludible ir construyendo una forma de «cosmo-polis». Cuál se el método para esbozar esa y qué fuerza normativa pueda tener son tal vez dos de los mayores problemas.

Por el momento, tres caminos parecen ofrecerse en el ámbito filosófico:

1) Uno de ellos sería el abierto por Rawls sobre todo a partir de Liberalismo político (1993) y claramente esbozado en El derecho de gentes (1993) ${ }^{24}$. Se

20 Para la religión civil ver S. GINER, «Religión civil», en Diálogo Filosófico, 21 (1991), págs. 357-387; A. CORTINA, Ética sin morah págs. 134 ss.

21 R. BEINER, "Introduction. Why Citizenship Constitutes a Theoretical Problem in the Last Decade of the Tweentieth Century?», R. BEINER (ed.), Theorizing Citizenship, págs. 1-28.

22 K. O. APEL, La transformación de la filosofia, Madrid, Taurus, 1985, II.

23 K. O. ApEL, "Globalización y necesidad de una érica universal. El problema a la luz de una concepción pragmático-trascendental y procedimental de la ética discursiva", en Debats, n1 66 (1999), págs. 48-67.

24 J. RAWLS, Liberalismo político, Barcelona, Crítica, 1996; "El derecho de gentes», en S. SHUTE y S. HuRLEY, De los derechos humanos, Madrid, Trotta, 1008, 47-86; Collected Papers (edited by Samuel Freeman), Harvard University Press, 1999. 
trataría en él de diseñar un concepto moral de la justicia, en principio, aceptado por las distintas doctrinas comprehensivas del bien, que conviven en una sociedad democrática y pluralista, y más adelante, adelgazar esa concepción de forma que pueda extenderse a todos aquellos pueblos cuya forma política no es la democracia liberal, pero que sí respetan en cierta forma los derechos humanos.

2) El segundo camino tendría unas raíces más marcadamente sociohistóricas, y tiene un buen ejemplo es la vía que señala Walzer en algunos de sus escritos, pero muy especialmente en Thick and Thin $(1994)^{25}$. Según Walzer, el procedimiento de construir un punto de vista moral universal, que consiste en elevarse kantianamente a la abstracción, tiene el inconveniente de no resultar efectivo para las gentes que, a fin de cuentas, viven en comunidades concretas, en las que los distintos valores y bienes tienen unas connotaciones muy determinadas. Quien desee conectar con las personas debe hablar ese lenguaje, enraizado en tradiciones y eticidades concretas, que ellas entienden: debe emplear un lenguaje espeso (thick), propio del "maximalismo moral". Mientras que el punto de vista moral abstracto (thin), el del "minimalismo moral", se extiende universalmente, pero a costa de perder comunicabilidad.

En una línea semejante a la propuesta por Walzer caminarían, a mi juicio, quienes, desde el Parlamento de las Religiones mundiales, están intentando detectar los elementos éticos comunes a todas ellas ${ }^{26}$.

3) La ética discursiva, ligada a la tradición kantiana, se presenta como una ética de la justicia (similar en esto a la rawlsiana), no de la vida buena, pero universalista en sus pretensiones, en la medida en que entiende que la estructura comunicativa y argumentativa de los seres humanos hace que cada uno de ellos sea un interlocutor válido con el que es posible sintonizar. El etnocentrismo no es insuperable. El hecho de que las pretensiones de validez sean un presupuesto irrebasable de la argumentación, y que una de esas pretensiones sea la de corrección normativa, permite construir una ética universal ${ }^{27}$.

25 Thick and Thin. Moral Argument at Home and Abroad, Univ. of Notre Dame Press, 1994. Hay trad. cast. en Madrid, Alianza, 1996.

26 H. KÜNG/K. J. KuSCHEL (eds.), Hacia una ética mundial Madrid, Trotta, 1994.

27 K. O. APEL, Transformación de la filosofia, II; Estudios éticos, Alfa, Barcelona, 1986; K. O. APEL: Verdad y Responsabilidad, Paidos, Barcelona, 1992; Diskurs und Verantwortung, Frankfurt, Suhrkamp, 1988; Auseinandersetzungen; J. HABERMAS, Conciencia moral y acción comunicativa, Península, Barcelona, 1985; "On the Pragmatic, the Ethical, and the Moral 
4) Una cuarta posibilidad consistiría en tomar como punto de partida la ética cívica ya presente en las sociedades con democracia liberal, desvelar sus rasgos y tratar de analizar en qué medida podría ir siendo ya compartida por distintas sociedades con distintas culturas, y en qué medida puede ser objeto de una fundamentación filosófica. El modelo, aunque dialógico, tendría por base el triplete kantiano: el ideal (moral) del reino de los fines sólo puede alcanzarse en comunidades políticas concretas fomentando una comunidad ética con «leyes públicas de virtud» ${ }^{28}$.

\section{Una base existente: la moral cívica}

Llegar a la conclusión de que una sociedad pluralista es aquélla en que los distintos grupos sociales comparten una moral cívica no ha sido tarea fácil en sociedades acostumbradas a pensar en el binomio "dogmatismo moral-relativismo». Convencer a los esquemáticos de que «tertium datun, y de que no sólo puede darse un tercio, sino incluso más, porque una moral cívica no es dogmática, pero tampoco relativista, y que tampoco son necesariamente dogmáticas o relativistas las morales plurales que una sociedad vive, ha sido verdaderamente costoso. Pero ya parece haber cierto reconocimiento de que la moral cívica, no sólo es posible, sino incluso existente. ¿Cuáles serían sus rasgos?

En principio, no puede consistir en recurrir a un modelo determinado de filosofia moral compartido por los miembros de una escuela filosófica, sino a algún tipo de moral inserto en la vida cotidiana. Si aceptamos la distinción usual entre la moral vivida en la vida cotidiana y la filosofía moral, no cabe duda de que la moral que debe inspirar la legislación positiva de una sociedad debe proceder del mundo de la vida de esa sociedad. Como bien decía Kant, el

Employments of Practical Reason", en Justification and Application, Cambridge and London, The MIT Press, 1993, págs. 1-18. Facticidad y validez, La inclusion del otro; «Justicia y solidaridad", en K. O. APEL, A. CoRTinA, D. MiChelini, J. DE ZAN, Ética comunicativa y democracia, Crítica, Barcelona, 1991; Trotta, 1998. Entre nosotros: A. CoRTINA, Razón comunicativa y responsabilidad solidaria, Salamanca, Sígueme, 1985; Ética minima, Madrid, Tecnos, 1986; Etica sin moral; Ética aplicada y democracia radical J. CONILL, El enigma del animal fantástico, Madrid, Tecnos, 1991; J. Muguerza, Desde la perplejidad, Madrid, F. C. E., 1991; D. GarCIA MarZÁ, Ética de la justicia, Madrid, Tecnos, 1992.

28 I. KaNT, Die Religion innerhalb der Grenzen der blossen Vernunft, VI., págs. 1-202; A. CORTINA, "El comunitarismo universalista de la filosofía kantiana", en J. CarVAJAL (coord.), Moral, derecho y politica en Immanuel Kant, Univ. de Castilla-La Mancha, 1999, págs. 241-252. 
filósofo puede facilitar la fórmula para dilucidar qué máximas son leyes morales, pero los deberes forman parte de la vida cotidiana, en la que obviamente también influyen las doctrinas filosóficas, pero no la componen. Y, por otra parte, debe tratarse de un tipo de moralidad que de algún modo comparte el conjunto de esa sociedad, entendiendo por «conjunto» no la mayoría numérica, sino el tipo de conciencia que presta cohesión a esa sociedad.

La ética cívica constituye, pues, el background ético de una sociedad moralmente pluralista, y por esa razón es capaz de crear en torno a ella cohesión social. No es una religión civil, en el sentido que Rousseau daba al término, como ya hemos comentado, sino un tipo de ética que oficia de gozne entre la ética personal, la ética de las distintas esferas de la vida social y el derecho.

Ante los retos de las nuevas tecnologías, los países occidentales elaboran documentos conjuntos, que orientan a su vez las legislaciones positivas de los países concretos y que constan habitualmente de tres partes: una científica, una ética y una jurídica. Y, cuando no los elaboran conjuntamente, se esfuerzan por conocer los documentos éticos de los restantes países ideológicamente cercanos a la hora de elaborar los suyos; de suerte que las diferencias éticas y jurídicas entre estos países son cada vez menores.

Podría decirse entonces que si los límites entre las distintas civilizaciones pueden trazarse teniendo en cuenta la religión que está o estuvo en el trasfondo de cada una de ellas ${ }^{29}$, cada vez más es una ética cívica común la que va uniendo a los países de tradición judeo-cristiana (Europa, América Latina, Estados Unidos, Australia). Si una ética semejante puede contener el germen de una ética global es lo que importa ir averiguando.

Se haría realidad entonces el sueño kantiano de una comunidad ética, regida - al menos verbalmente - por leyes morales comunes, en estrecho contacto con una comunidad politica, regida - al menos verbalmente- por algunas leyes legales comunes. Sin embargo, no es fácil aclarar cuál es la naturaleza de esa ética, si tiene algún contenido o es meramente procedimental, cuál es su relación con el derecho y qué fuerza obligatoria pyeden tener sus exigencias, sobre todo por dos razones: 1) porque se trata de un tipo de ética que debe corresponder al êthos de una sociedad política concreta y, sin embargo, pretender de algún

29 S. P. HuNTIGTON, The Clash of civilizations and the remaking of world order, New York, Simon \& Schuster, 1996. 
modo universalidad, pretender acceder al nivel de la Moralität, 2) porque se ha ido gestando de forma contingente como un hecho social, pero, para tener fuerza obligatoria, debe llevar en su seno un núcleo racional normativo con la fuerza de esa realidad racional que Hegel denominaba "Wirklichkeit» frente a la mera «Realität». De la mera facticidad contingente puede extraerse normatividad social, pero no moral, ni siquiera jurídica a largo plazo; es lo "vernünftig» lo que es "wirklich». Por eso es necesario tratar de descubrir desde una hermenéutica critica en qué consiste esta ética cívica ya wirklich, cuál es su núcleo racional-efectivo y en qué relación se encuentra con el derecho y la política.

Los rasgos de esta ética cívica son, en principio, los siguientes ${ }^{30}$ :

1) La ética civil es una realidad social y no un constructo filosófico, forma parte de la Lebenswelt propia de una sociedad pluralista, porque consiste en el conjunto de valores y principios que ya comparten los grupos de esa sociedad que proponen modelos de vida buena.

2) Es el tipo de ética que vincula a las personas en tanto que ciudadanas y por eso únicamente puede tener implantación en países cuyos miembros son ciudadanos, y no súbditos ni vasallos.

3) Es dinámica. Es la cristalización de los valores compartidos por distintas propuestas de vida buena. Esas propuestas podrían denominarse "éticas de máximos", puesto que cada una de ellas propone una jerarquización de bienes capaz de proporcionar una vida buena, y ofrece además los fundamentos, las "premisas mayores" del razonamiento por el que se concluye que ésa es la mejor forma de vida. La ética civil es una "ética de mínimos compartidos por las éticas de máximos y por la cultura política propia de Estados de Derecho.

4) La ética cívica es una ética pública, aunque también lo son las éticas de máximos, porque no hay ninguna ética privada, ni tampoco "no-pública", sino que todas tienen vocación de publicidad, de darse a conocer al público a través de la opinión pública, con razones comprensibles y admisibles.

Por tanto, la diferencia entre ética cívica de mínimos y éticas de máximos no consiste en que la primera esté implantada en la esfera pública y las segun-

30 A. CORTINA, Etica minima, Ética aplicada y democracia radical, Hasta un pueblo de demonios. Ética pública y sociedad, Madrid, Taurus, 1998; Ciudadanos como protagonistas, Barcelona, Círculo de Lectores/Galaxia Gutenberg, 1999. 
das en la privada, o en que la ética ć́vica exija razones públicas y las éticas de máximos exijan razones no públicas, sino en la forma en la que obligan: el cumplimiento de la ética cívica puede exigirse moralmente a la sociedad (aunque no imponerse mediante sanción externa, cosa que sí puede hacer el derecho), mientras que las éticas de máximos deben invitar a seguir su modelo de vida buena, pero no pueden exigir su cumplimiento, ni menos aún imponerlo mediante sanción externa.

El ámbito de la ética cívica es el de la justicia, que es un ámbito de exigencia, no sólo de invitación (éticas de máximos), pero tampoco es un ámbito de imposición o coacción externa (derecho).

5) La ética civil es una ética de los ciudadanos, propia de la sociedad civil $y$, en este sentido, conviene señalar sus diferencias con otras tres formas de interpretar filosóficamente la ética pública, con las que no se identifica.

a) Como ética de los ciudadanos, no se identifica con la "moral civil» de que hablaba Durkheim y que no es sino ética estatal ${ }^{31}$.

b) Tampoco se identifica con el modelo de "ética pública», que han hecho suyo algunos seguidores de Hart. Desde esta última perspectiva, se entiende por "ética pública" un tipo de moralidad que tiene vocación de incorporarse al derecho positivo, orientando sus fines y sus objetivos. Por eso esta ética pública recibe el nombre de "moralidad crítica" cuando todavía no se ha incorporado al derecho positivo y sirve como criterio para juzgar a éste, recibe el nombre de «moralidad legalizada o positivizadas cuando se ha incorporado al derecho positivo, y se dice de ella que «alcanza su perfección cuando se convierte en derecho" ${ }^{32}$.

En realidad nunca una ética alcanza su perfección al convertirse en derecho, tampoco una ética pública a la que damos el nombre de "ética cívica» para dejar claro que sí puede orientar el derecho justo, pero tiene sobre todo como meta incorporarse en las actitudes de los ciudadanos, convertirse en convicción y costumbre, formar parte de ese êthos de la sociedad, que nunca puede reducirse a las normas jurídicas, sino que siempre las trasciende.

31 E. DURKheim, Professional Ethics and Civic Morals, London, Routledge\&Kegan paul Ltd., 1957.

32 G. PECES, Ética, poder y derecho, Madrid, Centro de Estudios Constitucionales, 1995. 
c) La ética cívica guarda una gran semejanza con lo que Rawls llama una concepción moral de la justicia. Sin embargo, se diferencia de ella en los siguientes rasgos al menos:

En primer lugar, la meta de la ética cívica no es política, en el sentido liberal de la expresión. No pretende asegurar la estabilidad de una constitución democrática, sino posibilitar que los ciudadanos refuercen aquellos valores que ya les unen y que son expresión de una razón que los ha ido reconociendo-creando históricamente. Crea cohesión social y permite construir proyectos compartidos.

En segundo lugar, la ética cívica no nace con el afán de resolver conflictos judiciales, aunque puede ayudar a hacerlo, ni tiene por modelo de racionalidad el del Tribunal Supremo de Justicia. Es muy posible que la sociedad europea no esté todavía tan judicializada como la norteamericana, donde numerosos trabajos sobre filosofía moral y política (no sólo sobre filosofía del derecho) tienen su origen en sentencias judiciales, y donde hasta tal punto el modelo de razón judicial impregna la cultura que el modo de argumentar en la Corte Suprema llega a convertirse para Rawls en modelo del uso público de la razón ${ }^{33}$.

Si en la filosofía moral kantiana es preciso aplicar el test del imperativo categórico en su triple formulación para comprobar si una Handlungsmaxime puede convertirse en ley moral; si en la filosofía política de Kant el soberano debe someterse a la «cuarta formulación del imperativo categórico para uso de la soberanía" (según la cual, "el soberano no puede promulgar más leyes que las que el pueblo hubiera podido querer"), el "Gedankenexperiment" que propone Rawls para comprobar si los argumentos se ajustan al proceder propio de la razón pública consiste en imaginar si son los que admitiría la Corte Suprema. Con lo cual el utribunal de la razón práctica» coincide con el de la Corte Suprema.

En tercer lugar, entre la ética cívica y la concepción moral de la justicia rawlsiana existe una diferencia de nombre, que no es sólo nominal, sino también de nivel lógico de reflexión, puesto que la expresión "concepción moral de la justicia" es una expresión filosófica, que recoge hermenéuticamente los contenidos de un consenso entrecruzado. La expresión «ética cívica» es asumible

33 J. RaWLS, Liberalismo político, p. 289. 
en el mundo vital y eso permite institucionalizarla de forma más clara. Buen modo de transitar de la Moralität a la Sittlichkeit consiste en poner a las realidades sociales nombres socialmente reconocibles. Lo cual es todavía más necesario en el mundo ético, que no cuenta con Parlamentos, ni con Iglesias, sino que tiene que ser forjado por la ciudadanía.

Por último, y como veremos más adelante, para justificar racionalmente los contenidos de la ética cívica es totalmente insuficiente el modelo filosófico hermenéutico-coherencial y el recurso a un paradigma contractualista. Una reconstrucción de su fuerza obligatoria requiere apelar a una hermenéutica crítica que descubre los valores que acompañan al paradigma del reconocimiento recíproco y las actitudes y procedimientos racionalmente exigidos por él.

\section{Cuatro modelos de fundamentación ética}

En efecto, la tarea de la filosofía en relación con la ética cívica consiste, en principio, en tratar de descubrir su contenido en las distintas esferas de la vida social ${ }^{34} \mathrm{y}$, en segundo lugar, en dilucidar si vivir según ellos puede exigirse, si la ética ć́vica tiene fuerza normativa. Porque si únicamente ocurre que las sociedades occidentales han ido llegando históricamente a coincidencias éticas, sólo puede pedirse a los ciudadanos que simulen valorarlas positivamente dentro de una cultura de lo «éticamente correctom. Sólo si la razón ha ido configurando históricamente esas normas tiene sentido hablar de obligatoriedad. Importa, pues, remitir a un núcleo racional que no obligue sólo de forma hipotética ni sea el resultado de un convención, y cuya reconstrucción es sin duda tarea de la filosofía moral.

En el momento actual diversos candidatos se presentan para realizar esta tarea, siendo los que anteriormente mencionamos los que, en principio, parecen tener mayores probabilidades de éxito. Los tres primeros no se refieren a una ética cívica, como ya comentamos, mientras que sí lo hace el nuestro, que sería, obviamente, el cuarto. Los cuatro modelos serían entonces: el hermenéutico-coherencial, que utiliza el modelo jurídico contractual como un recurso para dar fuerza obligatoria a los contenidos morales; el socio-histórico y pragmatista, tagonistas. 
al que recurre un amplio sector del comunitarismo; el pragmático trascendental (Apel) o pragmático universal (Habermas), que reconstruye un paradigma social dialógico; pero como en su actual factura resulta insuficiente para fundamentar una ética cívica, precisaría ser complementado en un cuarto modelo, todavía sin nombre. De ellos trataremos brevemente.

1) El modelo hermenéutico-coherencial, propio del constructivismo político, trata de "comprender mejor" el "faktum" de la cultura política de las sociedades con pluralismo razonable, mediante conceptos, como persona moral, sociedad bien ordenada y posición original (momento hermenéutico), y desde esta comprensión intenta construir los principios de la justicia contando con el procedimiento del equilibrio reflexivo (momento coherencial) ${ }^{35}$. Ante un proceder semejante conviene decir que la renuncia al constructivismo moral puede tener sus ventajas políticas, pero imposibilita fundamentar la obligación moral: sólo los ciudadanos que de facto tengan un sentido de lo razonable estarán dispuestos a asumir virtudes "políticas", como la tolerancia, el respeto mutuo, la civilidad, el sentido de la equidad o la cooperación social equitativa.

Por otra parte, el paradigma contractuah que funciona como recurso para "comprender mejor" la cultura política, es, en sus distintas versiones, un modelo de derecho privado, traspasado al ámbito político, en el que puede disenar la figura del Leviatán, democratizarse en "ciudadanos libres e iguales", o intentar elaborar unas normas "por acuerdo", pero carece de fuerza exigitiva para fundamentar el tipo de obligación moral que requiere una ética cívica.

El interés egoista como base del contrato (Leviatán) o ese mismo interés, atemperado por la "razonabilidad", es impotente para obligar a quienes deseen beneficiarse de las ventajas del Estado de Derecho sin pagar peaje. Comprender mejor la cultura política democrática a la que se ha accedido históricamente y el sentido de la justicia inserto en ella no obliga moralmente a quienes no se sientan moralmente implicados. La figura del free rider es inevitable, pero también la del ciudadano consciente de que puede ser obligado a cumplir mandatos jurídicos, pero no se siente afectado por obligaciones morales.

2) En el contexto comunitarista existe una marcada tendencia a adoptar, como método de investigación, un método socio-histórico o de «interpretación

35 N. HOERSTER, "John Rawls'Kohärenztheorie der Normenbegründung", en O. HOFFE (Hg.), Über Jobn Rawls Theorie der Gerechtigkeit, Frankfurt, Suhrkamp, 1977, págs. 57-76. 
crítican (Walzer), o bien pragmático (Etzioni) o bien político (Barber), en vez de «salir de la caverna" a contemplar el mundo de las ideas, lo cual resta fuerza obligatoria para quienes no se sientan a gusto en la caverna.

Por otra parte, el pensamiento comunitario encuentra serias dificultades al intentar justificar ese núcleo de "Moralität», de pretensión de universalidad que se contiene en la ética cívica. Porque no se trata sólo de que en determinados países los contenidos éticos de la ética cívica formen parte del êthos de esa sociedad, sino que esos valores y principios pretenden valer universalmente, pretenden traspasar los contextos concretos de acción. Lo cual es, sin lugar a dudas, una puerta abierta al cosmopolitismo ${ }^{36}$.

3) El modelo de la pragmática trascendental o universal está capacitado para fundamentar el carácter de obligación de la ética cívica puesto que reconstruye las condiciones irrebasables de la acción comunicativa y, por lo tanto, accede al nivel de las exigencias racionales. Por otra parte, su reconstrucción, propia de una hermenéutica crítica, permite reconocer el carácter dialógico de la razón, a través de la categoría de reconocimiento recíproco, al que se obliga cualquier ser dotado de competencia comunicativa, no sólo para coordinar comunicativamente sus acciones, sino también para dilucidar si una norma de acción es vigente o válida ${ }^{37}$. Por otra parte, el modelo social del que da razón este tipo de reconstrucción pragmática y hermenéutica es el de comunidades políticas, dotadas de una ética cívica que, no por pertenecer al ethôs concreto deja de pretender universalidad. La ética cívica se configura con razones "éticas", pero sobre todo "morales".

4) Sin embargo, la ética del discurso, por su pretensión de ser «axiológicamente neutral» y de limitarse a los procedimientos racionales para la justificación de normas, ha caído en un procedimentalismo escueto, que corre el peligro de perder las dimensiones de lo moral que le confieren fuerza motivadora, y no sólo obligatoriedad racional. Por eso importa ir extrayendo los elementos axiológicos y «aretológicos", que están implícitos en los procedimientos, si es que la ética discursiva desea, no sólo fundamentar la ética cívica, sino prestar motivaciones para la obligación moral.

En este sentido podríamos ir extrayendo los siguientes: la libertad, entendida como autonomía de los hablantes, que no es sólo pragmática (capacidad

37 A. Cortina y J. Conill, "Pragmática Trascendental". 
de elevar pretensiones de validez y de aceptarlas o rechazarlas), sino también moral (capacidad de orientarse por intereses universalizables); la libertad, entendida como participación en las distintas esferas en las que se toman decisiones que afectan a una persona; el reconocimiento de que un hablante competente es una persona y debe ser tenida en cuenta en cuantas decisiones le afecten; el imperativo de la no instrumentalización reciproca, como condición necesaria para llegar a tener conciencia de lo justo y lo injusto; la igualdad de condiciones del diálogo, que exige la igualación material y cultural de los interlocutores virtuales y actuales, ya que, en caso contrario, es imposible cualquier pretensión de aproximación a la simetría (exigencia que va incluso más allá de los "derechos de $2 .^{\text {a }}$ generación"); la solidaridad con las redes sociales que hacen posible la supervivencia de los "pronombres personales"; el reconocimiento del valor de la comunidad lingüística de pertenencia pero, a su vez, de una comunidad de hablantes universal.

Desde esta perspectiva pueden exigirse, aunque no imponerse mediante coacción externa los contenidos de una ética cívica que tiene su fundamento, no en el consenso fáctico, sino en la exigencia racional del reconocimiento recíproco. Habida cuenta de que ese reconocimiento no se limita a los miembros de comunidades políticas concretas, sino que se extiende a todo ser dotado de competencia comunicativa, tal vez sea éste el modelo de ética cívica no de legión civil - que puede servir de base moral para ir contruyendo una ciudadanía cosmopolita. Hacer público su contenido sería indispensable para hacer efectivo el fin de la política (la paz perpetua) y el de la ética: un reino de los fines sin exclusión ${ }^{38}$.

38 Este trabajo se inscribe en el proyecto de investigación "La ética del discurso como núcleo de las éticas aplicadas", financiado por el Ministerio de Educación y Cultura (PB971419-C02-01). 